\section{Interaction of Anabolic Androgenic Steroids and Induced Tooth Movement in Rats}

Lilian Mary Karakida ${ }^{1}$ Cristiano Miranda de Araujoํ, Aline Cristina Batista Rodrigues Johann², Elisa Souza Camargoํㅜ, Orlando Motohiro Tanaka ${ }^{1}$, Odilon Guariza Filho ${ }^{1}$
'Graduate Program in Dentistry Orthodontics, School of Life Science, PUCPR - Pontifícia Universidade Católica do Paraná, Curitiba, PR, Brazil

${ }^{2}$ Graduate Program in Dentistry

- Histopathology, School of Life Science, PUCPR - Pontifícia Universidade Católica do Paraná, Curitiba, PR, Brazil

Correspondence: Odilon Guariza Filho, Rua Imaculada Conceição, 1155, Prado Velho, Curitiba, PR, Brasil. Tel: +55-41-3271-1555. e-mail: odilongfilho@gmail.com

\begin{abstract}
This study evaluated the interaction between tooth movement and two anabolic androgenic steroids (AAS), Deposteron ${ }^{\circledR}$ and Nebido ${ }^{\circledR}$. One hundred Wistar rats were divided into 3 groups: control (C) $n=30$, Nebido experimental $(N) n=35$ and Deposteron experimental (D) $n=35$. The control group was subdivided into 6 subgroups: 1, 2, 3, 5, 7 and 14 . The experimental groups were subdivided into 7 subgroups: $0,1,2,3,5,7$ and 14 , which corresponded to the day of animal's euthanasia after applying orthodontic force. Orthodontic devices were used to induce tooth movement using $50 \mathrm{cN}$ of reciprocal force between the maxillary right first molar and the maxillary incisors. After euthanasia, the tissues were processed and stained with hematoxylin and eosin (HE) and tartrateresistant acid phosphatase (TRAP). Osteoclasts, Howship's lacunae and blood vessels were quantified. Groups N and D showed acceleration in the reorganization of the periodontal ligament compared to group $C$. The peak of the histological events occurred in group $C$ on day 5 and in groups $\mathrm{N}$ and $\mathrm{D}$ on day 3 after installation of the orthodontic device. There was a statistically significant difference in the number of osteoclasts $(p<0.05)$ between groups N3 and C3, and between groups N3 and D3. Supra-physiological doses of the AAS Nebido ${ }^{\circledR}$ and Deposteron ${ }^{\circledR}$ altered the number of osteoclasts, Howship's lacunae and blood vessels, accelerating the reorganization of the periodontal ligament, resulting in accelerated biological effects from the induced tooth movement in rats.
\end{abstract}

Key Words: steroids, tooth movement, orthodontics.

\section{Introduction}

The continuous striving for esthetic self-improvement drives a great number of people to resort to a wide range of methods to achieve their goal. Orthodontic treatment corrects dental and skeletal deficiencies and is one of the options for esthetic correction of the face. Another alternative for improving body esthetics is the use of medications that facilitate muscular enlargement; these are mostly used by young people.

Anabolic androgenic steroids (AAS), synthetic hormones derived from the male hormone testosterone, are the most frequently used medications for muscle growth. AAS have two main types of therapeutic effects: androgenic and anabolic. Androgenic effects are specifically related to reproductive function and secondary male characteristics. Anabolic effects stimulate the growth and maturation of non-reproductive tissues. This is the desired effect among people who use AAS without therapeutic indication because AAS stimulate muscle growth, improving body esthetics (1).

Pre-adolescents, adolescents and adults seeking to improve physical appearance and increase muscular performance may misuse these substances. The illegality of obtaining AAS and their potential adverse effects do not seem to reduce their inappropriate use without a medical prescription $(2,3)$.

Long-term use of AAS alters body constitution, resulting in greater muscle mass and reduced gynoid fat mass without affecting bone mineral density (4). In a general population survey, men who were long-term AAS users shared common characteristics with illegal substance users (5). Other studies described a change in the growth pattern of the craniofacial complex, characterized by an increased total head length and elongated maxillary and mandibular incisors, in Wistar rats $(6,7)$. Gebhart et al. (8) found an increase of the vertical and horizontal growth of the mandible in rats subjected to AAS compared to rats subjected to placebos.

Patients undergoing orthodontic treatment may be using anabolic steroids, which can lead to adverse and undesirable effects that are contrary to the objectives of orthodontic treatment. The medical professional must ascertain the habits of the patient, guiding and intervening if necessary. Lack of research on the interaction between AAS and orthodontic tooth movement and knowing the 
influence of these substances on bone metabolism (5-8) motivated the delineation of this study.

The main objective of this study was to evaluate and compare the interaction of anabolic androgenic steroids (Deposteron ${ }^{\circledR}$ and Nebido ${ }^{\circledR}$ ) use, during induced tooth movement in rats, in the following aspects: osteoclasts, Howship's lacunae and blood vessels.

\section{Material and Methods}

The study was approved by the Ethics Committee for the Use of Animals (CEUA) of the University and registered under protocol number 492-2. The study subjects were one-hundred 9-week-old male Wistar rats (Rattus norvegicus albinus) weighing approximately 300-350 g. The medications used were Deposteron ${ }^{\circledR} 200$ mg (Testosterone Cypionate; Sigma Pharma, Hortolândia, SP, Brazil) and Nebido $^{\circledR} 250$ mg (Testosterone Undecanoate; Bayer, São Paulo, SP, Brazil). The anabolic steroids were administered twice a week, $1.25 \mathrm{mg}$ per dose (2.5 mg/week), which is considered a supra-physiological dose in rats (9-11). The AAS were administered by intramuscular injection into the rectus femoral muscle, alternating the right and left sides with each dose. After 20 days of AAS injections, the orthodontic devices to induce tooth movement were installed.

The animals were then divided into 3 groups: control (C), Nebido (N) and Deposteron (D). The control group $(n=30)$ was subdivided into 6 subgroups: 1, 2, 3, 5, 7 and 14. The experimental group Nebido $(n=35)$ and Deposteron $(n=35)$ were subdivided into 7 subgroups: $0,1,2,3,5,7$ and 14, which corresponded to the day of animal's euthanasia after applying orthodontic force. (Table 1).

Orthodontic movement was induced using a nickeltitanium closed coil spring (G\&H ${ }^{\circledR}$ Wire Company, Hanover, Germany) that applied a $30 \mathrm{gF}$ reciprocal force between the maxillary right first molar and maxillary central incisors, and was standardized using a dynamometer gauge (Dentaurum, number 1005004). The rats were sedated using an intramuscular injection of $1.8 \mathrm{mg} / \mathrm{kg}$ ketamine (Vetanarcol ${ }^{\circledR} ;$ Konig, Avellaneda, Argentine) and $1.1 \mathrm{mg} / \mathrm{kg}$ xylazine (Rompun ${ }^{\circledR} ;$ Bayer) and the coil spring was inserted. The tying wire encircled the crown of the maxillary right first molar, while attaching to one end of the spring, and the other end was attached to the maxillary right incisor using a tying wire and fixed with composite resin (Charisma ${ }^{\circledR}$;
Heraeus Kulzer, Hanau, Germany) (Fig. 1).

The animals were euthanized using an overdose of anesthetic solution (sodium pentobarbital), intraperitoneal injection. Following dissection and separation of the right side maxilla, the material was fixed in 10\% neutral formalin for $72 \mathrm{~h}$. The specimens were decalcified for approximately 12 weeks in a 4.13\% EDTA aqueous solution. Transverse 4-mm-thick sections obtained from the mesiobuccal root of the maxillary first molars were cut and stained.

After the demineralization was confirmed, the sections were embedded in paraffin and cross-sections were obtained in the neck region of the first maxillary molar. The intermediate root, alveolar bone and periodontal ligament were observed in all sections. The sections were stained with hematoxylin and eosin (HE) and TRAP.

The compression side was examined (the mesial aspect of the first upper right molar) as it is the side where the tooth was moved by the applied force. The distal face of the first maxillary right molar was the traction side and the periodontal ligament was the tension side.

HE staining was used to identify and quantify the number of blood vessels, osteoclastic cells and Howship's lacunae. The organization of collagen fibers and the morphology of the fibroblasts were examined on the compression and traction sides of the periodontal ligament adjacent to the intermediate root of the first maxillary right

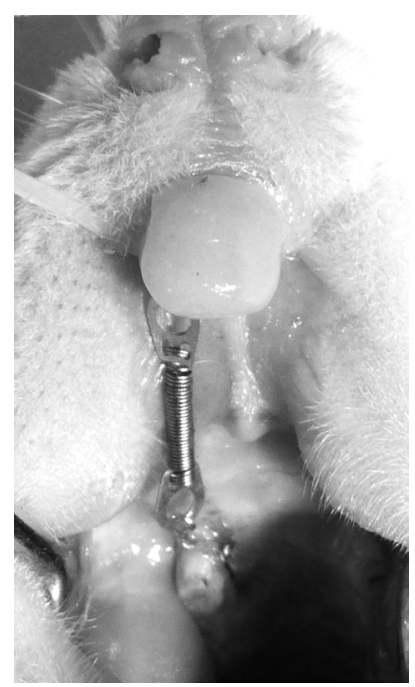

Figure 1. Orthodontic device installed.

Table 1. Animal groups and examination timese

\begin{tabular}{|c|c|c|c|}
\hline Control Group & 30 rats & No medication & $\begin{array}{l}\text { Death after 1, 2, 3, 5, } 7 \text { and } 14 \text { days following } \\
\text { installation of the orthodontic device }\end{array}$ \\
\hline $\begin{array}{l}\text { Nebido Experimental } \\
\text { Group }\end{array}$ & 35 rats & $\begin{array}{l}\text { AAS Nebido }{ }^{\circledR} \text { administered for } 20 \text { days before } \\
\text { the installation of the orthodontic device }\end{array}$ & $\begin{array}{c}\text { Death after } 0,1,2,3,5,7 \text { and } 14 \text { days following } \\
\text { installation of the orthodontic device }\end{array}$ \\
\hline $\begin{array}{l}\text { Deposteron } \\
\text { Experimental Group }\end{array}$ & 35 rats & $\begin{array}{l}\text { AAS Deposteron }{ }^{\circledR} \text { administered for } 20 \text { days before } \\
\text { the installation of the orthodontic device }\end{array}$ & $\begin{array}{c}\text { Death after } 0,1,2,3,5,7 \text { and } 14 \text { days following } \\
\text { installation of the orthodontic device }\end{array}$ \\
\hline
\end{tabular}


molar. Presence or absence of overlapping resorption was analyzed near the intermediate root; areas of hyalinization were assessed on all the roots of the first maxillary right molar.

Following the analysis of the data obtained by light microscopy to confirm the osteoclast count, the sections were stained with tartrate-resistant acid phosphatase (TRAP; Sigma-Aldrich, St. Louis, MO, USA) and contrasted with hematoxylin according to the manufacturer's instructions. The cells were considered to be osteoclasts if they were multinucleated, TRAP- positive and located on or near the surfaces.

To compare the experimental groups at time 0 (zero) for the 3 continuous variables was used the non-parametric Mann-Whitney $U$ test, since the sample size was $n=5$. The chi-square test was used for categorical variables to identify whether there was dependence between the variables.

To compare the times for each experimental group ( $D$ and $N$ ), was used the chi-square test for categorical variables and one-way ANOVA for continuous variables. This choice was based on the fact that despite each time was represented by 5 samples, similar mean and median values were observed indicating symmetrical distribution $\Xi$ of the data. When ANOVA indicated differences within both the Nebido and the Deposteron groups, the nonparametric Games-Howell test of multiple comparisons for heterogeneous variances was used to identify which times differed among them.

In order to compare if there were differences in the categorical variables among the 3 groups, regardless of time, among time regardless of group, and simultaneously considering group $X$ time, the chi-square test was used. Two-

Table 2. Comparison of 3 variables according to group $\mathrm{X}$ time

\begin{tabular}{llllllll}
\hline Variable & GT & GT & Mean & SD & Mean & SD & p value \\
\hline \multirow{2}{*}{ Osteoclast } & C3 & N3 & 7.4 & 4.3 & 14 & 4.3 & $0.00097^{*}$ \\
& C3 & D3 & 7.4 & 4.3 & 9 & 3.7 & 0.33659 \\
& N3 & D3 & 14 & 4.3 & 9 & 3.7 & $0.01579^{*}$ \\
& & & & & & & \\
$\begin{array}{l}\text { Howship's } \\
\text { lacunae }\end{array}$ & C3 & N3 & 17 & 7.2 & 22 & 7.4 & $0.0029^{*}$ \\
& D3 & 17 & 7.2 & 14 & 7.1 & 0.2821 \\
& D3 & 22 & 7.4 & 14 & 7.1 & $0.0497^{*}$ \\
Blood vessels & C3 & D3 & 4.6 & 4.9 & 18 & 3.2 & 0.99586 \\
& N3 & D3 & 20.4 & 4.8 & 18 & 3.2 & 099995 \\
\hline
\end{tabular}

Source: Research data. GT: group x time. SD: Standard deviation. Note: *Statistically significant value when $\mathrm{p}<0.05$

506 way ANOVA, full factorial model, was used for continuous variables when it was possible to test differences among groups, time and the interaction of group $X$ time.

\section{Results}

Figures 2 to $5 \mathrm{~A}$ greater numeric mean of all the variables was observed in the Nebido and Deposteron experimental groups compared to the $\mathrm{C}$ group. There were statistically significant differences in comparing group and time between the osteoclast and Howship's lacunae variables $(p<0.05)$ (Table 2).

Nebido and Deposteron groups showed an accelerated rate of histological events compared to control group. The control group's peak of events occurred at $\mathrm{C} 5$, day 5 after the installation of the orthodontic device. In experimental $\mathrm{N}$ and D groups, these events occurred on day 3 (N3 and D3).

Howship's lacunae are indicative of active osteoclasts, resulting in an irregularity of the alveolar bone in the compression area. To confirm if there was active resorption in the alveolar bone, the Pearson correlation was performed. A statistically significant value of $p<0.01$ showed a strong relationship between osteoclast and Howship's lacunae, confirming active bone resorption. There was an increase in osteoclasts, followed by an increase in Howship's lacunae.

Observing the behavior of the Nebido group, in the group $X$ time relationship among the studied different variables, on day 3 there was a statistically significant difference in the number of osteoclasts and Howship's lacunae $(p<0.05)$ between the N3 X C3 and the N3 X D3 groups, as the Nebido group had the largest numeric mean. The numeric means of the osteoclasts were 14.0, 7.4 and 18.0 for N3 C3, and D3, respectively. There were no statistically significant differences in C3 X D3 ( $>0.05)$.

\section{Discussion}

The use of AAS by individuals seeking improved appearance or better muscular development is increasing. The doses used to obtain an anabolic effect are commonly supra-physiological. Studies show that doses equal to or over $500 \mathrm{mg} /$ week are considered supra-physiological for adult humans. A dose of $2.5 \mathrm{mg} /$ week was used in the present study, based on the proportionate weight of humans and rats. This is a supra-physiological dose for rats (9-13).

To evaluate the interaction of AAS and induced tooth movement, were chosen the maxillary teeth for application of force. According to Fracalossi et al. (14), the best tooth to choose for induced tooth 
movement is the maxillary right first molar because it has no continuous root formation and its roots are not close to the roots of the maxillary incisors (14). The maxillary incisors are considered anchor teeth because they have long, curved, massive roots, and continuous root formations. These factors were considered to define why the first maxillary right molar and upper incisors were used in this study. The intermediate roots of the first maxillary right molars of the rats were used for histological analysis.

Application of a $50 \mathrm{cN}$ force to activate the orthodontic device is equivalent to an approximately $2500 \mathrm{cN}$ force in humans (14). This is a high/heavy force and causes exaggerated resorption in human bone and teeth. Therefore, the force applied in the experiment would not be ideal in clinical orthodontics. However, the purpose of this study was to evaluate the microscopic aspects of orthodontic movement induced by continuous force, therefore a $50 \mathrm{cN}$ force was appropriate. The study did not intend to avoid exaggerated biological phenomena in the analyzed tissues. Different from a clinical situation, this study required
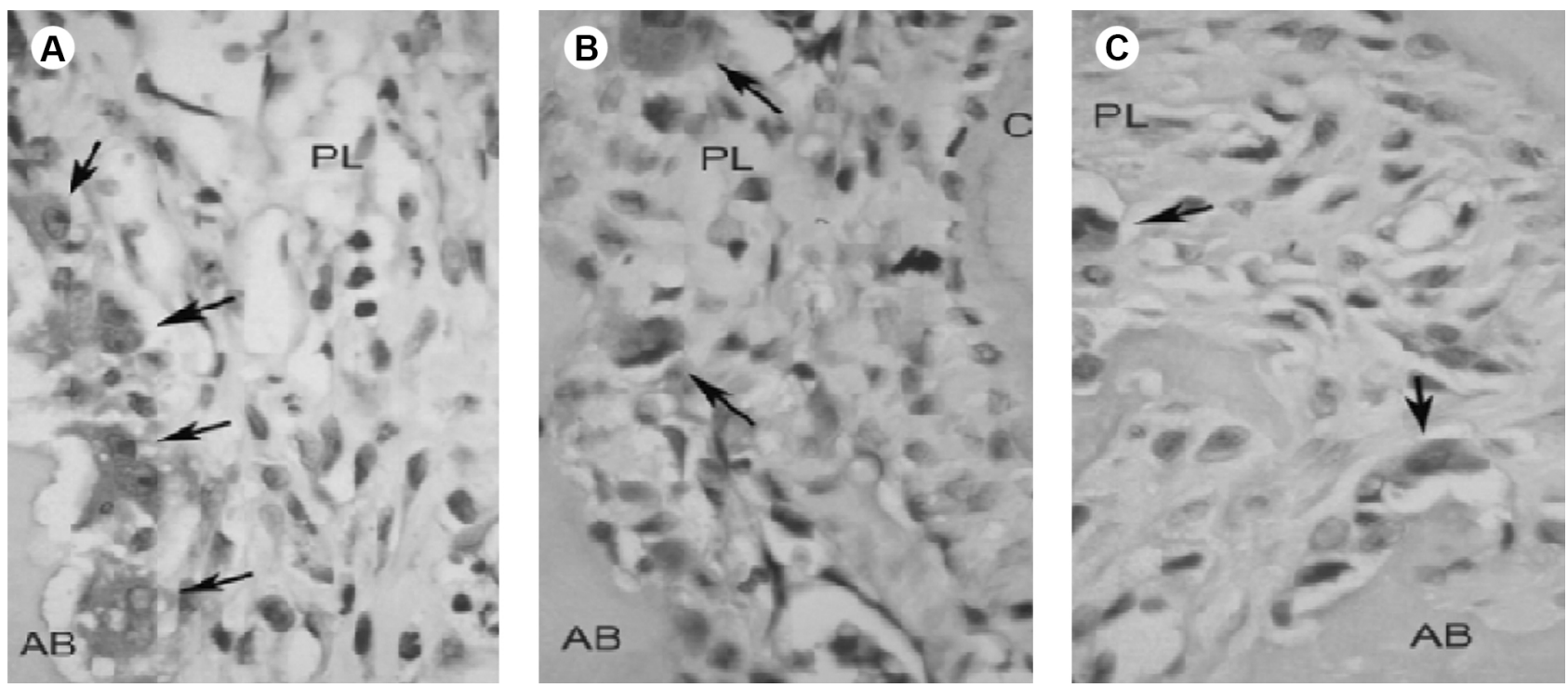

Figure 2. In the period of 3 days, a larger number of osteoclast cells (TRAP-positive cells, black arrows) were observed in group Deposteron (A) and group Nebido (B) compared with the Control group (C). AB: alveolar bone; PL: periodontal ligament; C: cementum (TRAP staining, magnification $\times 400)$.
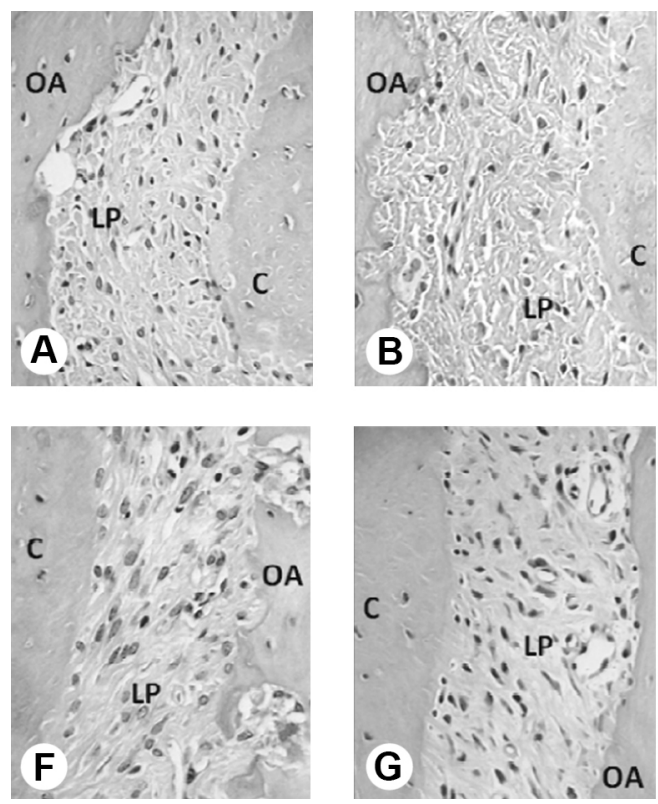
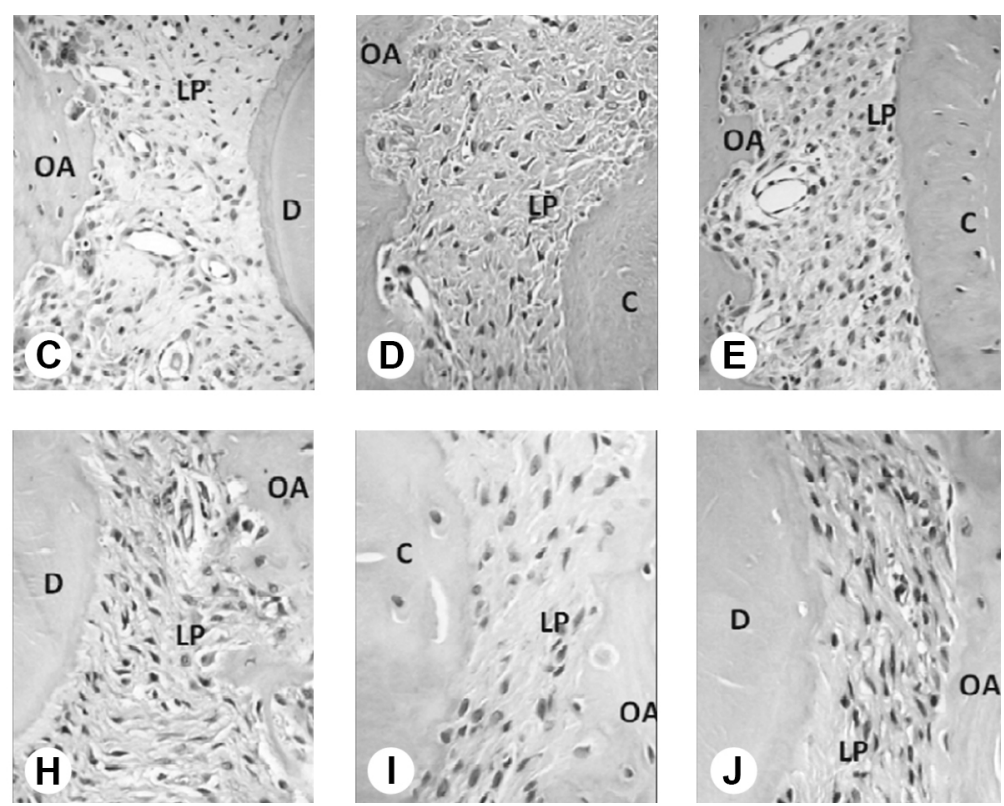
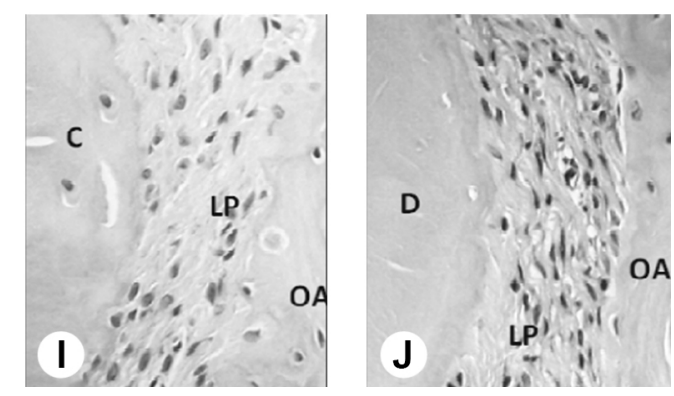

Figure 3. Control group. A, B, C, D, E: compression side of periodontal ligament at 1, 3, 5, 7 and 14 days. F, G, H, I, J: traction side of periodontal ligament at 1, 3, 5, 7 and 14 days. OA: alveolar bone; LP: periodontal ligament; D: dentin. C: cementum (HE staining, magnification $\times 200$ ) 
the presence of these biological phenomena in order to study some of the conditions that alter the microscopic characteristics of the tissues.

According to Fortunato (15), AAS have direct influence on bone resorption, which is characterized by an increase in osteoclasts. The use of steroids with androgenic activity accelerates the chronology of alveolar repair (16). Falanga (17) found that AAS also increase collagen synthesis, even without considerable increase in collagen fibers. There was an increase and advance in bone resorption and reorganization of the periodontal ligament collagen fibers in cases where AAS were administered. These data suggest that bone remodeling may have occurred precociously.
The results from the control group were similar to those of Heller and Nanda (18) and Macapanpan et al. (19) as they described a normal biological and tissue response of the periodontal ligament and alveolar bone if an orthodontically induced force is generated. There are no previous studies that showed interaction between AAS and induced tooth movement. Nevertheless, the present study reports statistically significant differences between the experimental and control groups.

When the number of osteoclasts and Howship's lacunae was compared between the groups at the same time period, the experimental groups Nebido and Deposteron had more significant events on day 3 , while the control group had
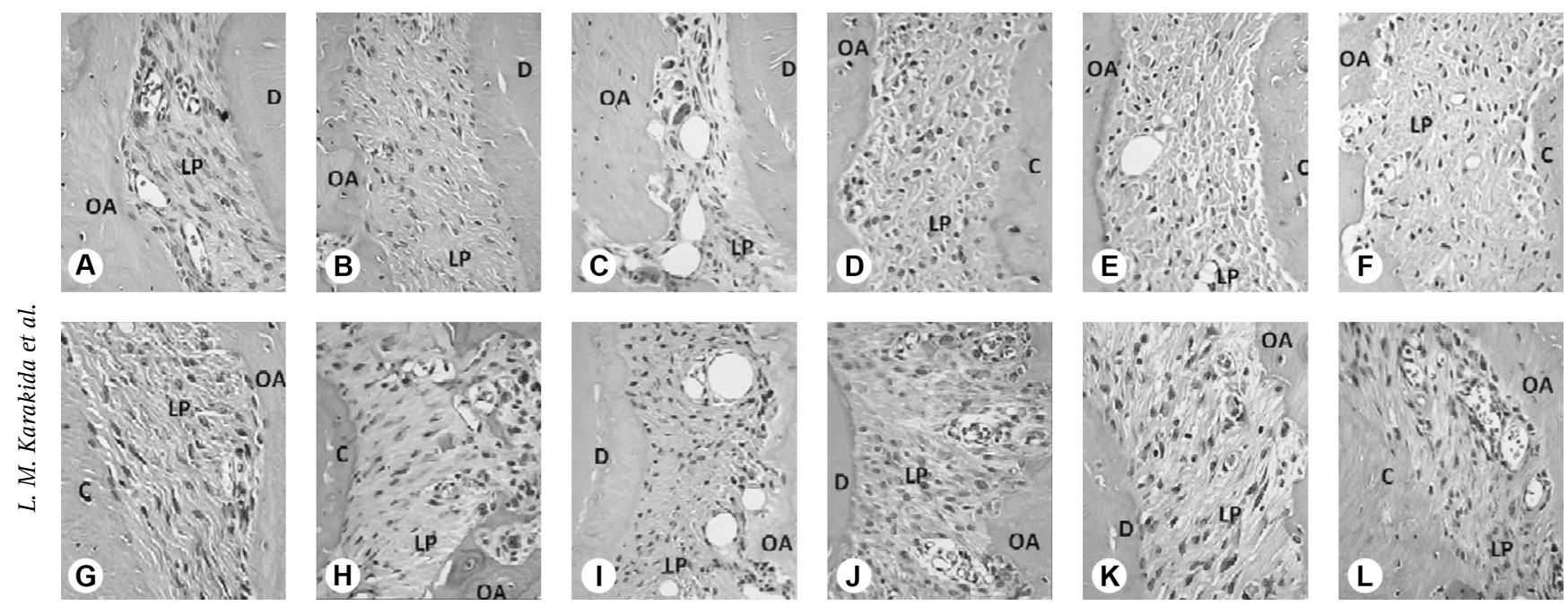

Figure 4. Deposteron experimental group. A, B, C, D, E: compression side of periodontal ligament at 0, 1, 3, 5, 7 and 14 days. G, H, I, J, K J: traction side of periodontal ligament at 0, 1, 3, 5, 7 and 14 days. OA: alveolar bone; LP: periodontal ligament; D: dentin. C: cementum (HE staining, magnification $\times 200$ ).
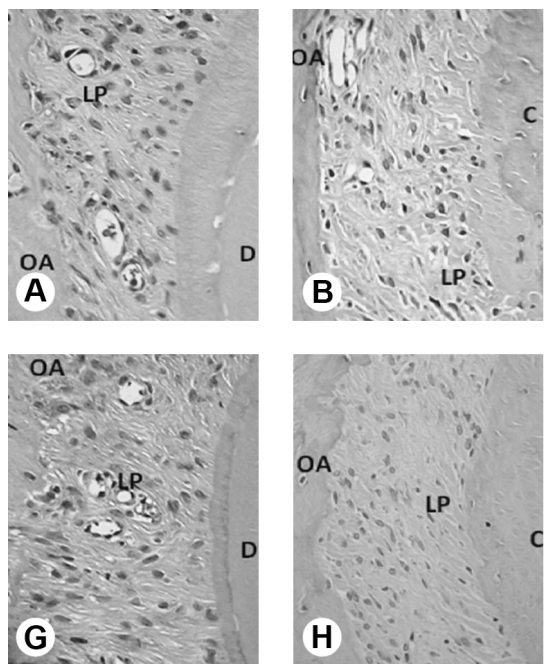
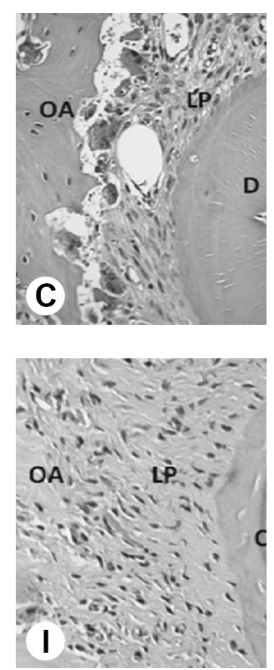
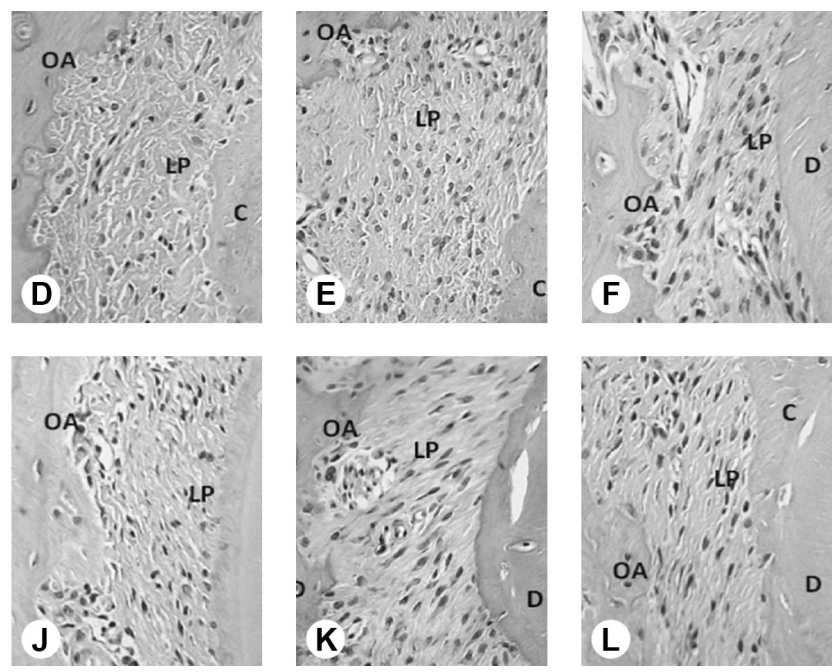

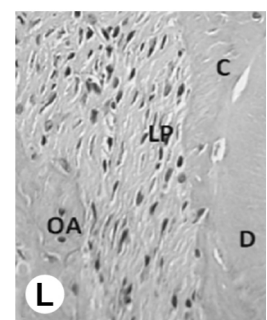

Figure 5. Nebido experimental group. A, B, C, D, E: compression side of periodontal ligament at 0, 1, 3, 5, 7 and 14 days. G, H, I, J, K J: traction side of periodontal ligament at $0,1,3,5,7$ and 14 days. OA: alveolar bone; LP: periodontal ligament; D: dentin. C: cementum (HE staining, magnification $\times 200)$. 
greater quantification on day 5 .

The numeric means of osteoclasts in the experimental groups were greater than in the control group, especially on day 3 , demonstrating an accelerated resorption in Nebido and Deposteron. There were statistically significant differences when C3 X N3 and D3 X N3 were compared $(p<0.05)$. There were no statistically significant differences in C3 X D3 ( $p>0.05)$. This bone resorption was more evident in Nebido may be due to the fact that anabolic steroids function as growth hormones, acting with a biphasic effect to accelerate resorption and delay in bone deposition $(20,21)$.

The organization of the collagen fibers on the compression side of the periodontal ligament began on day 5 in the experimental groups. In the control group, this organization was only noticed starting from day 14 following installation of the orthodontic device. Areas of hyalinization were found all days of the experiment, independent of time, proving that the use of force was exaggerated, exacerbating the biological effects of force on the periodontal ligament. In the experimental groups, the hypoxia of the periodontal ligament was reestablished more rapidly than in the control group, since areas of hyalinization were found in the control group until day 14. In the experimental groups, there was a significant reduction in these areas by day 7 . This suggests that there was a reduction in the remodeling and repair time of the tissue in the groups Nebido and Deposteron compared to control group. There is an increase in the amount of fibroblasts, synthesis of collagens and underlying substance when AAS are used, confirming the early reorganization of collagen fibers in the periodontal ligament (17).

Studies of the interaction of AAS and orthodontic movement have yet to be conducted in great depth. Orthodontic patients are becoming more discerning regarding esthetics and many may use these substances during orthodontic treatment. Because of this behavioral change, the interactions of medications and orthodontic treatment must be considered. In conclusion, the use of supra-physiological doses of the anabolic androgenic steroids Nebido ${ }^{\oplus}$ and Deposteron ${ }^{\oplus}$ in rats altered the number of osteoclasts, Howship's lacunae and blood vessels, accelerating the reorganization of the periodontal ligament, accelerating also the biological effects from induced tooth movement in rats.

\section{Resumo}

Este estudo avaliou a interação do movimento dentário entre dois esteróides anabólicos androgênicos (EAA), Deposteron ${ }^{\circledR}$ and Nebido ${ }^{\circledR}$. Cem ratos Wistar foram divididos em 3 grupos: controle (C) $n=30$, Nebido experimental (N) $n=35$ e Deposteron experimental (D) $n=35$. 0 grupo controle foi subdivido em 6 subgrupos: 1, 2, 3, 5, 7 e 14. Os grupos experimentais foram subdivididos em 7 subgrupos: $0,1,2,3,5$,
7 e 14, correspondendo ao dia da eutanásia do animal após aplicada a força ortodôntica. Um dispositivo ortodôntico foi utilizado para induzir a movimentação dentária com força recíproca de $50 \mathrm{cN}$ entre o primeiro molar superior direito e os incisivos superiores. Após a eutanásia, o tecido foi processado e corado com hematoxilina e eosina (HE) e fosfatase ácida tartarato-resistente (TRAP). Osteoclastos, lacunas de Howship e vasos sanguineos foram quantificados. Os grupos $\mathrm{Ne}$ D demonstraram aceleração na reorganização do ligamento periodontal comparado ao grupo C. 0 pico dos eventos histológicos ocorreu no grupo $\mathrm{C}$ no dia 5 e nos grupos $\mathrm{N}$ e $\mathrm{D}$ no dia 3, após a instalação do dispositivo ortodôntico. Houve diferença estatisticamente significante no número de osteoclastos $(p<0,05)$ entre os grupos N3 e C3 e entre os grupos N3 e D3. Doses supra-fisiológicas de EAA Nebido ${ }^{\circledR}$ and Deposteron ${ }^{\circledR}$ alteraram o número de osteoclastos, lacunas de Howship e vasos sanguíneos, acelerando a reorganização do ligamento periodontal, resultando na aceleração dos efeitos biológicos na movimentação dentária em ratos.

\section{References}

1. Ghaphery NA. Performance-enhancing drugs. Orthop Clin North Am 1995;26:433-442.

2. Faigenbaum $A D$, Zaichkowsky LD, Gardner DE, Micheli U. Anabolic steroid use by male and female middle school students. Pediatrics 1998;101:E6.

3. Silva L.S.M. MRLM. Use of anabolic-androgenic steroids among body builders in major gym centers in_São Paulo. Rev. Bras. Cienc. Farm. 2003;39:327-333.

4. Nordstrom A, Hogstrom G, Eriksson A, Bonnerud $P$, Tegner $Y$, Malm C. Higher muscle mass but lower gynoid fat mass in athletes using anabolic androgenic steroids. J Strength Cond Res 2012;26:246-250.

5. Hakansson A, Mickelsson K, Wallin C, Berglund M. Anabolic androgenic steroids in the general population: user characteristics and associations with substance use. Eur Addict Res 2012;18:83-90.

6. Barrett RL, Harris EF. Anabolic steroids and craniofacial growth in the rat. Angle Orthod 1993;63:289-298.

7. Noda K, Chang HP, Takahashi I, Kinoshita Z, Kawamoto T. Effects of the anabolic steroid nandrolone phenylpropionate on craniofacial growth in rats. J Morphol 1994;220:25-33.

8. Gebhardt A, Pancherz H. The effect of anabolic steroids on mandibular growth. Am J Orthod Dentofacial Orthop 2003;123:435-440.

9. Catlin DH, Murray TH. Performance-enhancing drugs, fair competition, and Olympic sport. JAMA 1996;276:231-237.

10. Parkinson $A B$, Evans NA. Anabolic androgenic steroids: a survey of 500 users. Med Sci Sports Exerc 2006;38:644-651.

11. Sinha-Hikim I, Artaza J, Woodhouse L, Gonzalez-Cadavid N, Singh AB, Lee Ml et al. Testosterone-induced increase in muscle size in healthy young men is associated with muscle fiber hypertrophy. Am J Physiol Endocrinol Metab 2002;283:E154-164.

12. Bhasin $S$, Woodhouse $L$, Casaburi $R$, Singh AB, Bhasin D, Berman N, et al.. Testosterone dose-response relationships in healthy young men. Am J Physiol Endocrinol Metab 2001;281:E1172-1181.

13. Wu FC. Endocrine aspects of anabolic steroids. Clin Chem 1997:43:1289-1292.

14. Fracalossi ACC SJM, Consolaro MFM-0, Consolaro A. Experimental tooth movement in murines: study period and direction of microscopic sections. Rev. Dent. Press Ortodon. Ortop. Facial 2009;14:143-157.

15. Fortunato RS, Rosenthal D, Carvalho DP. [Abuse of anabolic steroids and its impact on thyroid function]. Arq Bras Endocrinol Metabol 2007;51:1417-1424.

16. dos Santos-Pinto R, Okamoto T, de Castro AL. Pharmacological effect of nandrolone phenylpropionate on the healing of dental extraction wounds: a histological investigation in rats. J Nihon Univ Sch Dent 1970;12:57-61.

17. Falanga $V$, Greenberg AS, Zhou L, Ochoa SM, Roberts AB, Falabella A, et al.. Stimulation of collagen synthesis by the anabolic steroid stanozolol. J Invest Dermatol 1998;111:1193-1197.

18. Heller IJ, Nanda R. Effect of metabolic alteration of periodontal fibers on orthodontic tooth movement. An experimental study. Am J Orthod 1979;75:239-258. 
19. Macapanpan LC, Weinmann JP. The influence of injury to the periodontal membrane on the spread of gingival inflammation. J Dent Res 1954;33:263-272.

20. Carroll PV, Christ ER, Bengtsson BA, Carlsson L, Christiansen JS, Clemmons $\mathrm{D}$, et al.. Growth hormone deficiency in adulthood and the effects of growth hormone replacement: a review. Growth Hormone Research Society Scientific Committee. J Clin Endocrinol Metab 1998;83:382-395.
21. Simpson H, Savine R, Sonksen P, Bengtsson BA, Carlsson L, Christiansen $J S$, et al.. Growth hormone replacement therapy for adults: into the new millennium. Growth Horm IGF Res 2002;12:1-33.

Received April 13, 2017 Accepted May 22, 2017 